\title{
Measurement properties of the Short Form- 36 (SF-36) and the Functional Assessment of Cancer Therapy - Anemia (FACT-An) in patients with anemia associated with chronic kidney disease
}

\author{
Fredric O. Finkelstein ${ }^{1 *}$, Floortje van Nooten ${ }^{2}$, Ingela Wiklund ${ }^{3}$, Dylan Trundell ${ }^{4}$ and David Cella ${ }^{5}$
}

\begin{abstract}
Background: Anemia is a common and debilitating manifestation of chronic kidney disease (CKD). Data from two clinical trials in patients with anemia of CKD were used to assess the measurement properties of the Medical Outcomes Survey Short Form-36 version 2 (hereafter SF-36) and the Functional Assessment of Cancer Therapy-Anemia (FACT-An). The Vitality and Physical functioning domains of the SF-36 and the FACT-An Total, Fatigue and Anemia subscales were identified as domains relevant to CKD-associated anemia.

Methods: A total of 204 patients aged 18-80 years were included in the analyses that included internal consistency (Cronbach's alpha), test-retest reliability (intraclass correlation coefficients [ICCs]), convergent and known-groups validity, responsiveness, and estimates of important change.

Results: Both the SF-36 and the FACT-An had strong psychometric properties with high internal consistency (Cronbach's alpha: 0.69-0.93 and 0.79-0.95), and test-retest reliability (ICCs: 0.64-0.83 and 0.72-0.88). Convergent validity, measured by correlation coefficients between similar concepts in SF-36 and FACT-An, ranged from 0.52 to 0.77 . Correlations with hemoglobin $(\mathrm{Hb})$ levels were modest at baseline; by Week 9 , the correlations with $\mathrm{Hb}$ were somewhat higher, $r=0.23(p<0.05)$ for SF-36 Vitality, $r=0.22(p<0.05)$ for FACT-An Total, $r=0.26(p<0.001)$ for FACT-Fatigue and $r=0.22(p<0.01)$ for Anemia. Correlations with Hb at Week 13/17 were $r=0.28(p<0$. 001) for SF-36 Vitality and $r=0.25(p<0.05)$ for Role Physical; FACT-An Total correlation was $r=0.33(p<0$. 0001), Anemia was $r=0.28(p<0.001)$, and Fatigue was $r=0.30(p<0.001)$.

The SF-36 domains and Component Summary scores $(p<0.05-p<0.0001)$ demonstrated ability to detect change. For the FACT-An, significant differences $(p<0.05-p<0.0001)$ were observed between responder and non-responder change scores: important change score estimates ranged from 2 to 4 for Vitality and 2-3 for Physical functioning. Important change scores were also estimated for the FACT-An Total score (6-9), the Anemia (3-5), and Fatigue subscale (2-4).
\end{abstract}

Conclusions: Both the SF-36 Vitality and Physical function scales and the FACT-An Total, Fatigue and Anemia scales, are reliable and valid measures for assessing health-related quality of life in anemia associated with CKD.

Keywords: Anemia, Chronic kidney disease, Quality of life, Psychometric evaluation, SF-36, FACT-An

* Correspondence: fof@comcast.net

${ }^{1}$ Yale University, New Haven, CT, USA

Full list of author information is available at the end of the article

(c) The Author(s). 2018 Open Access This article is distributed under the terms of the Creative Commons Attribution 4.0 International License (http://creativecommons.org/licenses/by/4.0/), which permits unrestricted use, distribution, and reproduction in any medium, provided you give appropriate credit to the original author(s) and the source, provide a link to the Creative Commons license, and indicate if changes were made. The Creative Commons Public Domain Dedication waiver (http://creativecommons.org/publicdomain/zero/1.0/) applies to the data made available in this article, unless otherwise stated. 


\section{Background}

Anemia is common among patients with chronic kidney disease (CKD); the prevalence in US patients is estimated to be over 15\% [1]. An association between anemia and CKD stage has been identified, with anemia increasing in prevalence by disease severity from $8.4 \%$ in Stage 1 to $53.4 \%$ in Stage 5. Minutolo et al. [2] reported a 44\% prevalence of anemia across all CKD stages in patients who were not receiving dialysis, while McFarlane et al. estimated a prevalence of 50 to $70 \%$ across all stages [3].

Symptoms of anemia include fatigue, low energy, weakness, dizziness, and dyspnea $[4,5]$; symptom severity varies with the degree of anemia [6]. Persistent fatigue has been identified as one of the most debilitating symptoms both pre-dialysis and in dialysis disease stages $[7,8]$. The impact of fatigue varies widely, from being described as 'mild impairment' to greatly affecting daily functioning including, at times, basic activities of daily living [9]. Diminished aspects of health-related quality of life (HRQoL), such as functional and ambulatory impairment, and increased risk of falls, have all been identified as complications of anemia [10-14].

Patient-reported outcome (PRO) measures are frequently used to assess treatment efficacy in clinical trials [15]. Although used in some trials as primary endpoints (eg, a patient report of pain is required in the absence of objective clinical markers), PROs are often used to identify additional benefits associated with treatment, including symptom experience, functioning, and HRQoL. Thus, measurement of HRQoL as a primary outcome of treatment interventions in end-stage renal disease (ESRD), as well as a tool for clinicians to assess patient status, is an increasingly accepted research endpoint.

While earlier studies suggested a broad range of symptom improvement with anemia treatment, recent studies indicate that the domains of Vitality and Physical functioning are most beneficially affected by treatment $[6,16]$.

The Medical Outcomes Survey Short Form-36 (SF-36) is a generic, widely validated HRQoL measure that has been used in numerous research studies and clinical trials of CKD anemia [11, 17-25] with specific focus on the Vitality and Physical functioning domains $[6,16,26]$. Measurement properties of SF-36 have been assessed in patients with CKD, [27] but no corresponding data are available specifically for patients with CKD anemia.

The Functional Assessment of Cancer Therapy-Anemia (FACT-An) was developed to assess the impact of anemia on quality of life in patients with cancer-associated anemia $[28,29]$. Content validity was addressed during the development of the FACT-An and was based on interviews with patients with cancer-associated anemia, literature review, and expert input. The Total FACT-An score and the FACT Anemia and Fatigue score are of particular interest for use with anemia associated with CKD. Although the tool has been used in many oncology clinical trials, [30-33], data in the CKD population are lacking.

Both the European Medicines Agency [34] and the US Food and Drug Administration [35] require that new drugs under consideration for approval be tested in clinical trials with PRO endpoints that are specific and relevant to the proposed treatment population. Documentation of measurement properties of domains of PRO surveys in the target population is essential. The purpose of this study is to assess further the measurement properties of the SF-36 and the FACT-An with particular focus on domains of vitality/fatigue, anemia, and physical function, which most closely relate to CKD anemia. Data from two clinical trials in patients with CKD anemia who were not receiving dialysis or who were newly initiated on dialysis were used to evaluate the validity of SF-36 and the FACT-An in this sample.

\section{Methods \\ Patient sample}

Data were derived from two clinical trials that evaluated a hypoxia-inducing factor prolyl hydroxylase (HIF-PH) inhibitor in patients with CKD anemia. The trial designs were similar, but not identical, and allow the evaluation of the SF-36 and FACT-An questionnaires in patients with ESRD. Details of these trials including treatment interventions have been published previously [36-38]. Briefly, the first (NCT00761657) was a Phase 2, open-label, randomized trial in patients with anemia and Stage 3 or 4 CKD, who were not on dialysis (non-dialysis group) [36]. The patients were 18-70 years old with an $\mathrm{Hb}$ level $<10.5 \mathrm{~g} / \mathrm{dL}$ and an estimated glomerular filtration rate of $>15$ to $<60 \mathrm{~mL} / \mathrm{min} / 1.73 \mathrm{~m}^{2}$ pre-randomization. The second (NCT01244763) was a Phase $2 \mathrm{~b}$, randomized, open-label trial in newly initiated patients on dialysis (dialysis group) [37, 38]. The patients were $18-80$ years old with a pre-randomization $\mathrm{Hb}$ level $<10.0 \mathrm{~g} / \mathrm{dL}$. They had received hemodialysis or peritoneal dialysis for native kidney ESRD for a minimum of 2 weeks and a maximum of 4 months. Patients in both studies were not currently and had not previously received an erythropoietin-stimulating agent (ESA) or IV iron within 4 weeks of randomization.

\section{Study design}

In the non-dialysis trial, dosing strategies for the HIF-PH inhibitor were employed across six cohorts (with 24-25 patients per cohort). Patients attended weekly study visits during the treatment period (16 weeks for Cohorts A and B, and 24 weeks for Cohorts C 
through F). The FACT-An and the SF-36 questionnaires were administered at baseline, Week 9, Week 17 (Cohorts A-D only for SF-36), and Week 24 (Cohorts C-D only).

In the dialysis trial, approximately 12 patients were enrolled in each of five HIF-PH inhibitor treatment arms. The trial employed a 1:1:1 ratio for the first 36 patients to receive no iron supplementation, oral iron supplementation, and IV iron supplementation. Patients visited the clinic weekly during the 12-week treatment period, followed by a four-week post-treatment follow-up period. The FACT-An and SF-36 questionnaires were administered at baseline, Week 9, and Week 13.

Data used to characterize each patient sample were collected at baseline/during screening for both dialysis and non-dialysis patients. These included sociodemographic (date of birth, sex, and race/ethnicity) and clinical data (weight and height, pulse rate, blood pressure, respiratory rate, date of $\mathrm{CKD}$ diagnosis, date of anemia diagnosis, comorbid conditions, laboratory parameters, treatments received, and rescue medication use). $\mathrm{Hb}$ level was collected at baseline, Week 9, and Week 13/17 (dialysis/non-dialysis) as well as at other time points.

\section{Patient-reported outcome measures}

The SF-36 is designed to assess health concepts that are relevant across age, disease, and treatment groups in adults [39]. As well as a health transition item, the SF-36 contains eight domains: Physical functioning (10 items), Role-physical (4 items), Bodily Pain (2 items), General Health (5 items), Vitality (4 items), Social functioning (2 items), Role-emotional (3 items), and Mental Health (5 items). Two Component Summary scores, the Physical Component Summary (PCS) and the Mental Component Summary (MCS), can also be calculated with all scores using the norm-based approach (US population norm mean score for each domain and summary score is 50, with a standard deviation [SD] of 10) [40]. Anemia-related domains such as the Vitality and Physical functioning were previously identified to be of special interest $[6,16]$. A four-week recall was used for the SF-36 in both trials. Suggested important change scores have been reported by the instrument developers for each domain and Component Summary score based on the 2009 US general population [40]. The suggested change scores are appropriate for $T$-scores ranging from 30 to 40 . Where the $T$-score for the population exceeds this range, increasing the change score is recommended.

The FACT-An is designed to assess aspects of quality of life affected by anemia in patients with cancer [28]. Using a seven-day recall period, the 27 item FACT-General (FACT-G) includes four dimensions of well-being: Physical (7 items), Functional (7 items), Social/Family (SWB; 7 items), and Emotional (6 items).
The FACT-An also includes 13 fatigue-specific items (the Fatigue Subscale) plus an additional 7 items specific to anemia and unrelated to fatigue. Anemia subscales such as FACT-An Total and the Fatigue and Anemia subscales were of special interest. These last 20 items $(13+7)$ combine to form the Anemia subscale. Higher scores indicate better health status. An important change score estimate of 4 points for the Anemia total score and 3 points for the Fatigue score has previously been reported in patients with cancer [41]. In patients with CKD, a three-point or greater increase was previously identified as a clinically meaningful improvement on the FACT-Fatigue total score [42].

\section{Statistical analyses}

Unless stated otherwise, data from the two clinical trials were pooled at baseline and at Week 9. Week 17 data from the non-dialysis group were pooled with Week 13 data from the dialysis group. Pooling the data from the two trials provided a sufficiently large sample size and a greater range of impairment within a CKD patient sample for more effective testing of the measurement properties of SF-36 and FACT-An. All statistical tests were two-sided and significance level was set at $p<0.05$.

For the SF-36 domain/Component Summary scores and the FACT-An Total and subscale scores, descriptive statistics (mean, SD, median, and range) were calculated at baseline, Week 9, and Week 13/17.

\section{Reliability}

Cronbach's coefficient alpha was used to assess the internal consistency of the SF-36 domain scores and Component Summary scores and the FACT-An Total and relevant subscales at baseline. A Cronbach's alpha $\geq 0.70$ was considered an acceptable minimum value definition for good reliability [43]. Patterns of item-to-item correlations and item-to-total correlations, and the number of items in the subscale, were also considered. Alpha coefficients $>0.7$ indicated good internal consistency, $0.4-<$ 0.69 moderate internal consistency, and $<0.4$ low internal consistency reliability $[44,45]$.

Test-retest reliability was assessed in the subgroup of patients $(n=153)$ whose $\mathrm{Hb}$ level was classified as unchanged (average weekly $\mathrm{Hb}$ change within $\pm 0.5 \mathrm{~g} / \mathrm{dL}$ between Week 9 and Week 13/17 with no rescue therapy between these time points). The average weekly change in $\mathrm{Hb}$ was determined by comparing the weekly differences in $\mathrm{Hb}$ between Week 9 and every week from Week 10 to Week 13/17. Intraclass correlation coefficients (ICCs) were calculated to compare the SF-36 domain/Component Summary and the FACT-An Total and subscale scores at Week 9 and Week 13/17. An ICC $\geq 0.7$ indicated good, 0.4-0.7 moderate, and $<0.4$ poor test-retest reliability [44, 45]. 


\section{Validity}

Validity refers to the extent to which an instrument measures what it is intended to measure; it is typically assessed by examining correlations with other indicators of similar/related constructs [46]. Correlations of 0.10 are considered small, correlations between 0.30 and 0.50 are regarded as moderate, and correlations of 0.50 or more are considered large [47]. Spearman's rank-order correlation coefficients between the SF-36 domain/Component Summary scores and the FACT-An Total and subscale scores at baseline, Week 9, and Week 13/17 were used to assess convergent validity.

The SF-36 Vitality domain was previously identified as an important measure of disease impact resulting from anemia [6, 16], therefore the FACT-An Fatigue and Anemia subscales were expected to correlate more strongly with Vitality domain than other SF-36 domains. Known-groups validity was assessed to demonstrate the ability of the SF-36 and FACT-An instrument domain scores to differentiate between patients with varying levels of anemia, using $\mathrm{Hb}$ levels at baseline. The SF-36 and FACT-An domain scores were compared between the scores above and below the median $\mathrm{Hb}$ level at baseline using analysis of covariance (ANCOVA) with adjustments for gender and age. Similarly, for assessment of known groups validity, the SF-36 Physical Function and Vitality median split domain scores were used to establish the difference in the FACT-AN scores at baseline, while the FACT-An, FACT Anemia, and FACT Fatigue subscales median split were used to show that the baseline SF-36 scores differed. Groups were defined by $\mathrm{Hb}$ level (<11 g/dL vs $\geq 11 \mathrm{dg} / \mathrm{dL} ;<$ median vs $\geq$ median) or relevant SF-36 domain/ score and FACT-An specified domain score ( $<$ median vs $\geq$ median).

\section{Ability to detect change}

The focus of this study was to document the ability of each instrument to detect change; thus, all analyses were conducted using pooled data only, i.e., no analyses were performed by treatment or doses. Using ANCOVA models, the ability to detect change of the SF-36 domain/Component Summary scores and the FACT-An Total and subscale scores was assessed by comparing the mean scores of $\mathrm{Hb}$ responders and non-responders at baseline to Week 9 and baseline to Week $13 / 17$ change scores, controlling for age, gender, and baseline score (FACT-An and SF-36).

Responders were defined with the same clinical criteria used in the trial protocols:

\section{a. Hb responders}

Baseline $\mathrm{Hb}$ level $>8 \mathrm{~g} / \mathrm{dL}:$ Hb level $>11.0 \mathrm{~g} / \mathrm{dL}$ with $\geq 1.0 \mathrm{~g} / \mathrm{dL}$ increase
Baseline $\mathrm{Hb}$ level $\leq 8 \mathrm{~g} / \mathrm{dL}: \mathrm{Hb}$ level $>2.0 \mathrm{~g} / \mathrm{dL}$ increase at the end of Weeks 7-9 and Weeks 11$13 / 15-17$

b. SF-36 responders

Vitality (SF-36) responders: > 3-point increase in SF-36 Vitality score

Physical functioning (SF-36) responders: > 3-point increase in SF-36 Physical functioning score

Physical Component Summary (SF-36) responders

-- an increase of two points in SF-36 Physical

Component Summary score;

c. FACT-An responders

FACT-An Anemia responders: > 4-point increase in FACT-An Anemia score

FACT-An Fatigue responders: > 3-point increase in FACT-An Fatigue subscale score.

\section{Estimating important change scores}

Methods for interpreting the importance of quality of life changes in clinical research generally follow two approaches: distribution-based and anchor-based. A distribution-based approach is based on statistical characteristics of the obtained samples. This approach relies on the distribution of scores and the related effect size of change scores. An anchor-based approach compares the change in a patient reported outcome, such as patient judgement of change with a second, external measure of change, which serves as the anchor. Anchor-based assessments offer the advantage of linking the change in a given score to the patient's perspective (which is captured by the anchor). Because we had relevant clinical anchors, we employed both approaches.

A minimally important difference (MID) refers to the "smallest difference in score in the domain of interest that patients perceive as important, (either beneficial or harmful, and which would lead the clinician to consider a change in the patient's management" [48]. Because determination of the "minimally" important difference or change can vary by context, and because of some misuse of the concept, this term has fallen out of favor, with terms such as "important change scores" or "clinically important differences" increasingly used instead [49].

Previously reported important change scores for the SF-36 for the general population vary from 2 to 3 [40]. Clinically important differences reported for the FACT-An targeted domains have been estimated at 3 points for the Fatigue subscale, 4 FACT-An points for the Anemia subscale, and 6 points for the Total score [41].

In the present study, the SF-36 Vitality, Physical functioning domain, and Physical Component Summary score were used as anchors to estimate important change scores on the FACT-An. Similarly, FACT-An scores were used as anchors to estimate important change scores on the SF-36. Only patients achieving a 
pre-defined meaningful change score in these domains (from baseline to Week 9 or to Week 13/17) were included in the analyses. The mean SF-36 or FACT-An change scores (from baseline to Week 9 or to Week 13/ 17) for these patients thereby provided an estimate of an important change score. The meaningful change score was defined as 3-4 point increase in the SF-36 Vitality score, a 3-4 point increase in the SF-36 Physical functioning score, and a 2-3 point change in the SF-36 Physical Component Summary score.

For SF-36 change scores, the first anchor used a 4-7 point increase in the FACT-An Anemia subscale score to define the "minimally improved" category to assess the change in the SF-36 domain/Component Summary scores associated with a minimal change in condition. A second anchor used a 3-5 point increase in the FACT-An Fatigue subscale score.

The SF-36 Vitality domain (important change of 3 points) and Physical functioning domain (3 points) and the Physical Component Summary (2 points) were used to calculate important change score estimates for the FACT-An Total score and Fatigue and Anemia subscales. Similarly, the following FACT-An MID anchors [41] were used for SF-36 linking: FACT-An Total score of 6, FACT-An Anemia subscale score of 4, and a FACT-An Fatigue subscale score of 3 points.

\section{Results}

\section{Patient demographics and clinical characteristics}

The mean age of patients was 60.2 years (Table 1 ). The gender distribution differed by trial; $63.4 \%$ of patients in the non-dialysis group were female vs $47.5 \%$ in the dialysis group. Patients in the non-dialysis group were typically older than patients in the dialysis group. The statistically significant differences between the dialysis and non-dialysis groups should be interpreted with caution given the smaller number of patients in the dialysis group.

Comorbid conditions and disease history were generally similar; however, diabetes was more common in the non-dialysis group (61.4\% vs 18.6\%). A high proportion of the non-dialysis group had diabetic (55.9\%) or hypertensive nephropathy (53.1\%), whereas in the dialysis group, the most common CKD history category was ischemic nephropathy (42.4\%). Additional details of the two patient groups can be found in respective trial publications $[36,38]$.

\section{Descriptive statistics}

Low baseline SF-36 domain and Component Summary scores for the total sample were found for Physical functioning, Role-physical, General Health, and Physical Component Summary score (Table 2). Scores approaching the 2009 general US population mean (50.0) were found for Vitality, Mental Health, and Mental Component Summary score. The scores indicate that these patients predominantly experienced physical rather than mental impairments.

Baseline scores were similar for both trial samples for Physical functioning, Vitality, and the Physical Component Summary score, whereas Role-physical, Role-emotional, and Mental Health domains, and the Mental Component Summary score were all lower in dialysis patients.

At baseline, the mean FACT-An Total score was 131.5 (SD: 30.0), the mean Fatigue subscale score was 34.2 (SD: 11.5), and the mean Anemia subscale score was 53.9 (SD: 15.0). (Table 2) The FACT-An Well-Being subscales ranged from 17.8 to 21.0. Improvements were observed by Week 9 in the FACT-An Total and all subscale scores, except for the Social Well-Being where a small decrease was identified. These scores were relatively stable, with similar mean values reported at Week 13/17.

Table 1 Demographic Characteristics for Non-dialysis (NCT00761657) and Dialysis (NCT01244763) Patient Groups and Pooled Total

\begin{tabular}{llll}
\hline Characteristic & NCT00761657 (N=145) & NCT01244763 (N=59) & All Patients ${ }^{\mathrm{a}}(N=204)$ \\
\hline Age (years), mean (SD)*** & $50.2(14.0)$ \\
Gender (female), n (\%)* & $64.4(11.3)$ & $28(47.5 \%)$ & $120(58.8 \%)$ \\
Race, n (\%)**15.1) & & $8(3.9 \%)$ \\
$\quad$ Asian & $92(63.4 \%)$ & $2(3.4 \%)$ & $44(21.6 \%)$ \\
Black or African-American & $6(4.1 \%)$ & $2(3.4 \%)$ & $146(71.6 \%)$ \\
$\quad$ White & $42(29.0 \%)$ & $54(91.5 \%)$ & $6(2.9 \%)$ \\
Other & $92(63.4 \%)$ & $1(1.7 \%)$ & \\
Ethnicity (N, \%)*** & $5(3.4 \%)$ & & $48(23.5 \%)$ \\
Hispanic/Latino & & $1(1.7 \%)$ & $156(76.5 \%)$ \\
Not Hispanic/Latino & $47(32.4 \%)$ & $58(98.3 \%)$ & \\
\hline
\end{tabular}

${ }^{*}<0.05,{ }^{* *}<0.001,{ }^{* * *}<0.0001$ comparing dialysis and non-dialysis patients

a. Subjects with at least one intake of study medication and at least one valid SF-36v2 completion

b. Other includes Mexican, mixed, Filipino, Spanish and Latin American

SD standard deviation 
Table 2 Descriptive Statistics for the SF-36 and FACT-An at Baseline

\begin{tabular}{|c|c|c|c|c|c|c|}
\hline Measure & $\mathrm{N}$ & Mean \pm SD & Range & Median & Mode & Missing $\mathrm{N}, \%$ \\
\hline \multicolumn{7}{|l|}{ SF-36 } \\
\hline Physical Functioning & 194 & $38.2 \pm 11.1$ & $17.1-57.0$ & 38.1 & 36.0 & $0(0.0 \%)$ \\
\hline Role-physical & 194 & $40.1 \pm 11.2$ & $17.7-56.9$ & 39.7 & 37.3 & $0(0.0 \%)$ \\
\hline Role-emotional & 193 & $41.3 \pm 13.7$ & $9.2-55.9$ & 44.2 & 55.9 & $1(0.5 \%)$ \\
\hline Vitality & 194 & $47.7 \pm 12.0$ & $20.9-70.8$ & 49.0 & 45.9 & $0(0.0 \%)$ \\
\hline Mental Health & 194 & $48.4 \pm 11.5$ & $19.0-64.1$ & 52.8 & 52.8 & $0(0.0 \%)$ \\
\hline Social Functioning & 194 & $45.3 \pm 11.5$ & $13.2-56.9$ & 45.9 & 56.9 & $0(0.0 \%)$ \\
\hline Bodily Pain & 194 & $47.3 \pm 11.2$ & $19.9-62.1$ & 46.1 & 62.1 & $0(0.0 \%)$ \\
\hline General Health & 194 & $39.5 \pm 9.5$ & $16.2-62.5$ & 38.6 & 32.9 & $0(0.0 \%)$ \\
\hline Physical Component Summary & 194 & $40.0 \pm 9.4$ & $17.0-64.0$ & 40.7 & 27.5 & $0(0.0 \%)$ \\
\hline Mental Component Summary & 194 & $48.0 \pm 11.5$ & $14.3-67.3$ & 49.6 & 32.1 & $0(0.0 \%)$ \\
\hline \multicolumn{7}{|l|}{ FACT-An } \\
\hline Total FACT-An score & 197 & $131.5 \pm 30.0$ & $44.0-185.0$ & 131.0 & 122.0 & $1(0.5 \%)$ \\
\hline Total FACT-G score & 197 & $77.6 \pm 17.0$ & $25.0-106.8$ & 78.0 & 72.0 & $1(0.5 \%)$ \\
\hline Physical Well Being & 198 & $20.9 \pm 5.5$ & $2.0-28.0$ & 22.0 & 25.0 & $0(0.0 \%)$ \\
\hline Functional Well Being & 197 & $18.0 \pm 6.5$ & $2.0-28.0$ & 18.0 & 28.0 & $1(0.5 \%)$ \\
\hline Social Well Being & 198 & $21.0 \pm 5.8$ & $2.0-28.0$ & 22.0 & 28.0 & $0(0.0 \%)$ \\
\hline Emotional Well Being & 197 & $17.8 \pm 4.7$ & $0.0-24.0$ & 19.0 & 21.0 & $1(0.5 \%)$ \\
\hline Anemia subscale & 198 & $53.9 \pm 15.0$ & $14.0-80.0$ & 54.9 & 57.0 & $0(0.0 \%)$ \\
\hline Fatigue subscale & 198 & $34.2 \pm 11.5$ & $8.0-52.0$ & 35.5 & 28.0 & $0(0.0 \%)$ \\
\hline Trial outcome index & 197 & $92.7 \pm 24.6$ & $27.0-136.0$ & 92.0 & 72.0 & $1(0.5 \%)$ \\
\hline
\end{tabular}

a. Norm-based score based on 2009 US general population survey

Internal consistency and test-retest reliability

Good to excellent reliability coefficients were demonstrated for the SF-36 domain/Component Summary scores except the General Health Domain (0.69) and for the FACT-An Total score and all subscales (Table 3).
Overall, Cronbach's alpha scores were acceptable for both measures on all other domains, ranging from 0.76 to 0.95. Particularly high Cronbach's alpha scores were observed in the Physical functioning, Role-physical, and Role-emotional domains on the SF-36 as well as the

Table 3 Internal Consistency and Test-retest Reliability of the SF-36 and the FACT-An Subscales

\begin{tabular}{|c|c|c|c|c|c|c|c|c|c|}
\hline $\begin{array}{l}\text { SF-36 domain/Component Summary } \\
\text { score }\end{array}$ & $\mathrm{N}^{\mathrm{a}}$ & $\begin{array}{l}\text { Cronbach's } \\
\text { alpha }\end{array}$ & $N^{b}$ & $\begin{array}{l}\text { Test-retest } \\
\text { (ICC) }\end{array}$ & FACT-An total/subscale & $\mathrm{N}^{\mathrm{a}}$ & $\begin{array}{l}\text { Cronbach's } \\
\text { alpha }\end{array}$ & $N^{b}$ & $\begin{array}{l}\text { Test-retest } \\
\text { (ICC) }\end{array}$ \\
\hline Physical functioning & 188 & 0.90 & 77 & 0.83 & Anemia subscale & 190 & 0.92 & 76 & 0.83 \\
\hline Role-physical & 193 & 0.93 & 76 & 0.69 & Fatigue subscale & 196 & 0.93 & 76 & 0.80 \\
\hline Vitality & 193 & 0.82 & 75 & 0.64 & Total FACT-An score & 131 & 0.95 & 76 & 0.88 \\
\hline Role-Emotional & 193 & 0.93 & 77 & 0.74 & FACT-G score & 133 & 0.91 & 76 & 0.86 \\
\hline Mental Health & 193 & 0.81 & 77 & 0.75 & Functional Well-Being & 196 & 0.87 & 76 & 0.83 \\
\hline Social Functioning & 194 & 0.76 & 77 & 0.69 & $\begin{array}{l}\text { Physical Well-Being } \\
\text { subscale }\end{array}$ & 196 & 0.84 & 76 & 0.83 \\
\hline Bodily Pain & 194 & 0.88 & 77 & 0.74 & Social Well-Being & 137 & 0.80 & 76 & 0.76 \\
\hline General Health & 192 & 0.69 & 77 & 0.75 & Emotional Well-Being & 193 & 0.79 & 76 & 0.72 \\
\hline Physical Component Summary score & - & 0.92 & 76 & 0.81 & & & & & \\
\hline Mental Component Summary score & - & 0.90 & 76 & 0.75 & & & & & \\
\hline
\end{tabular}

Abbreviations: ICC intraclass correlation coefficient, FACT-An Functional Assessment of Cancer Therapy-Anemia, FACT-G Functional Assessment of Cancer Therapy-General, SF-36 Medical Outcomes Survey Short Form-36

a. Number of subjects at Baseline

b. Number of subjects with average weekly Hb change within +/- $0.5 \mathrm{~g} / \mathrm{dL}$ between Week 9 and Week 13/17 (study FGCL-4592-053/study FGCL-4592-041) and who have not received rescue therapy 
Anemia and Fatigue subscales on the FACT-An. Test-retest reliability was demonstrated for all domains and both summary scores, using $>0.6$ as an acceptable cut-off [50].

\section{Convergent and known-groups validity}

As expected, the SF-36 Vitality domain showed strong correlations with the FACT-An Fatigue and Anemia subscales $(r=0.76$ and $r=0.77$, respectively; Table 4). The correlations between the SF-36 and the FACT-An Anemia and Fatigue subscales generally were high.

The correlations with $\mathrm{Hb}$ level were modest, particularly at baseline where the $\mathrm{Hb}$ range was limited by trial inclusion criteria (Table 4). The correlations with $\mathrm{Hb}$ level at Week 9 and 13/17 were similar: SF-36 Vitality correlated with $\mathrm{Hb} r=0.28(p<0.001)$ and Role Physical score, $r=0.25(p<0.01)$, whilst the FACT-An Total had a correlation of $r=0.33(p<0.001)$, Anemia $r=0.28(p$ $<0.001)$, and Fatigue $r=0.30(p<0.001)$.

For the assessment of known groups validity, a median split of the predefined SF-36 and FACT An scores were used, as described earlier in the methods section. Highly significant differences were found for all the key FACT-An and SF-36 domains: the FACT-An scores split by the SF-36 Physical Functioning domain were: FACT-Anemia subscale score (mean 46.4, [SD 13.9]) vs 61.6(12.2), the FACT Fatigue subscale $28.9(10.8)$ vs. $39.7(9.5)$, and the Total FACT-An score $118.3(28.8)$ vs $145.0(25.0)$, all $p<0.0001$. Similarly, the corresponding median split using the SF-36 Vitality score and the SF-36 PCS scores were all highly significant for all the FACT-An domains FACT-Anemia., FACT Fatigue subscale and the FACT-An Total scores $p<0.0001$. The SF-36 results showed the same pattern, i.e., the SF-36 scores split

Table 4 Convergent Validity - Correlations Between SF-36 and the FACT-An Fatigue and Anemia Subscales

\begin{tabular}{lll}
\hline SF-36 domain/Component & \multicolumn{2}{l}{ FACT-An subscale } \\
\cline { 2 - 3 } Summary score & Anemia & Fatigue \\
\hline Physical functioning & $0.63^{* * *}$ & $0.60^{* * *}$ \\
Role-Physical & $0.64^{* * *}$ & $0.61^{* * *}$ \\
Vitality & $0.77^{* * *}$ & $0.76^{* * *}$ \\
Role-Emotional & $0.53^{* * *}$ & $0.52^{* * *}$ \\
Mental Health & $0.54^{* * *}$ & $0.52^{* * *}$ \\
Social Functioning & $0.66^{* *}$ & $0.67^{* * *}$ \\
Bodily Pain & $0.53^{* * *}$ & $0.53^{* * *}$ \\
General Health & $0.64^{* * *}$ & $0.61^{* * *}$ \\
Mental Component Summary score & $0.62^{* * *}$ & $0.62^{* * *}$ \\
Physical Component Summary score & $0.69^{* * *}$ & $0.66^{* * *}$ \\
\hline
\end{tabular}

Spearman's rank order correlation. ${ }^{* * *} p<0.001$

Abbreviations: FACT-An Functional Assessment of Cancer Therapy-Anemia,

SF-36 Medical Outcomes Survey Short Form-36
Table 5 Convergent Validity-Correlations ${ }^{\mathrm{a}}$ of FACT-An and SF36 Scales with $\mathrm{Hb}$ Level at Baseline, Week 9 and Week 13/17

\begin{tabular}{|c|c|c|c|}
\hline & \multicolumn{3}{|c|}{$\mathrm{Hb}$ level } \\
\hline & Baseline & Week 9 & Week 13/17 b \\
\hline \multicolumn{4}{|l|}{ FACT-An Total/Subscale } \\
\hline Total FACT-An score & $0.20^{*}$ & $0.22^{*}$ & $0.33^{* *}$ \\
\hline Total FACT-G score & $0.22^{*}$ & $0.20^{*}$ & $0.34^{* * *}$ \\
\hline Physical well-being subscale & $0.21^{*}$ & $0.17^{*}$ & $0.32^{* *}$ \\
\hline Functional well-being subscale & $0.22^{*}$ & $0.21^{*}$ & $0.29^{* *}$ \\
\hline Social/family well-being subscale & $0.18^{*}$ & 0.09 & $0.22^{*}$ \\
\hline Emotional well-being subscale & $0.16^{*}$ & $0.20^{*}$ & $0.30^{* *}$ \\
\hline Anemia subscale & 0.14 & $0.22^{*}$ & $0.28^{*}$ \\
\hline Fatigue subscale & 0.11 & $0.26^{* *}$ & $0.30^{* *}$ \\
\hline Trial outcome index & $0.19^{*}$ & $0.22^{*}$ & $0.32^{* *}$ \\
\hline \multicolumn{4}{|l|}{ SF-36v2 Domain/Component } \\
\hline Physical Functioning & 0.07 & 0.13 & 0.12 \\
\hline Role-physical & $0.24^{* *}$ & $0.23^{*}$ & $0.25^{*}$ \\
\hline Role-emotional & 0.12 & 0.13 & $0.25^{*}$ \\
\hline Vitality & $0.18^{*}$ & $0.23^{*}$ & $0.28^{* *}$ \\
\hline Mental Health & $0.23^{*}$ & $0.22^{*}$ & $0.27^{*}$ \\
\hline Social Functioning & 0.10 & 0.12 & $0.31^{* *}$ \\
\hline Bodily Pain & 0.00 & 0.10 & $0.25^{*}$ \\
\hline General Health & $0.17^{*}$ & $0.22^{*}$ & $0.26^{*}$ \\
\hline Mental Component Summary & $0.20^{*}$ & $0.18^{*}$ & $0.30^{* *}$ \\
\hline Physical Component Summary & 0.10 & $0.19^{*}$ & $0.22^{*}$ \\
\hline
\end{tabular}

a.Spearman's rank order correlation. ${ }^{*} p<0.05 ;{ }^{* *} p<0.001 ;{ }^{* * *} p<0.001$

b.Week 13 for NCT00671657; Week 17 for NCT01244763

by the median FACT-An score showed large and significant differences $(p<0.0001)$ for Physical Functioning 32.3(9.5) vs 43.8(9.4); and Vitality 39.5(13.5) vs. 55.5(8.3). A split by FACT-Anemia and the FACT-An Fatigue scales showed the same pattern for the SF-36 Physical Functioning and Vitality domains and were all highly significant $(p<0.001)$.

For the SF-36, using a median split of $\mathrm{Hb}$ level to define the group, a significant difference was found for the Vitality domain score at baseline, $p<0.05$ (Table 5). The FACT-An Total score, discriminated between groups based on a median split of $\mathrm{Hb}$ level. When comparing groups with an $\mathrm{Hb}$ level of $<11$ vs $\geq 11 \mathrm{~g} / \mathrm{DL}$ at Week 9, the FACT-An Total Score, and Anemia and Fatigue subscale produced significantly different scores $(p<0.05, p<0.01, P<0.01$, respectively).

\section{Ability to detect change}

Both the SF-36 and Fact-An demonstrated the ability to detect change. Small improvements (relative to baseline) were observed in all SF-36 domain and Component 
Summary scores. Despite a high baseline Vitality score in both trials, sizeable gains in Vitality were observed in both trials. Larger gains were observed in the dialysis group, with a greater than three-point increase by Week 13 for the Physical Component Summary score, and the Physical functioning, Role-emotional, Role-physical, and Vitality domains. Only the Vitality change score achieved this cut-off in the non-dialysis group by Week 9 or Week 17. Large improvements in FACT-An Total and all FACT-An subscale scores (except for the Social Well-Being) were shown at Week 9, and were relatively stable by Week $13 / 17$. When separating by trial, baseline mean scores were higher in the non-dialysis group for the FACT-An Total score and all subscale scores compared with the dialysis group, and gains were generally larger in dialysis group.

For FACT-An Anemia subscale-defined responders, significant differences between responders and non-responders were identified for all SF-36 domains and Component Summary change scores at both time points assessed. Similarly, significant differences were observed between responders and non-responders using FACT-An Fatigue-defined responders at Week 9 for all SF-36 scores, and for all except Physical functioning, General Health and PCS at Week 13/17.

Using SF-36 Vitality-defined responders, significant differences were identified for the FACT-An Total change score, Anemia and Fatigue subscale change scores $(p<0.001)$ at Week 9 and Week 13/17 $(p$ $<0.01)$. A similar pattern of results was identified using SF-36 Physical functioning-defined and Physical Component Summary-defined responders where significant differences were found for FACT-An Total, Anemia, and Fatigue subscale scores relative to baseline $(p<0.01)$.
Using $\mathrm{Hb}$ level to define responders, only the $\mathrm{Fa}$ tigue subscale produced significant differences at Week 9 between responders and non-responders based on $\mathrm{Hb}$ level/change $(p<0.05)$, whilst at Weeks 11-13/15-17, significant differences were identified for the FACT-An Total score, the and Physical Well-Being subscales $(p<0.05)$. Significant differences were also identified in the Fatigue, subscale at Week 13/17 $(p<0.05)$; however, the non-responder sample size was particularly low $(n=19-30)$ in these analyses at the later time points.

\section{Important change scores}

Table 6 shows the important change scores produced by each method for each SF-36 domain/Component Summary scores. The anchor-based methods were produced using relatively small sample sizes $(n=21-26)$. The estimates produced by linking were similar to the other anchor-based methods, and typically smaller than the distribution-based estimates. A central principle is that confidence in the estimate increases when the domains are more highly correlated with the anchor $[41,51,52]$. Of the anchors used, the FACT-An Anemia subscale had the strongest correlations with the target domains/ Component Summary scores. For the Physical functioning, Vitality, and Physical Component Summary domains, the following important change score estimates are recommended: Physical functioning: $2-3$ points; Vitality: 2-4 points; Physical Component Summary: 2-4 points.

For the FACT-An scores, distribution-based estimates were typically larger than anchor-based estimates, with 0.5 SD estimates larger than one SEM estimates for all scores except the Social Well-Being subscale (Table 7).

Table 6 SF-36: Important Change Score Estimates Using Distribution-based, Anchor-based, and Linking Methods

\begin{tabular}{|c|c|c|c|c|c|c|c|c|c|}
\hline $\begin{array}{l}\text { SF-36 Domain/Component } \\
\text { Summary score }\end{array}$ & $\begin{array}{l}1 \\
\text { SEM }\end{array}$ & $\begin{array}{l}0.5 \\
\text { SD }\end{array}$ & $\begin{array}{l}\text { Anemia 4-7, } \\
\text { Week } 9\end{array}$ & $\begin{array}{l}\text { Anemia 4-7, } \\
\text { Week 13/17 }\end{array}$ & $\begin{array}{l}\text { Fatigue 3-5, } \\
\text { Week } 9\end{array}$ & $\begin{array}{l}\text { Fatigue 3-5, } \\
\text { Week 13/17 }\end{array}$ & $\begin{array}{l}\text { Linking FACT- } \\
\text { An total }\end{array}$ & $\begin{array}{l}\text { Linking } \\
\text { anemia }\end{array}$ & $\begin{array}{l}\text { Linking } \\
\text { fatigue }\end{array}$ \\
\hline Physical functioning & 4.6 & 5.5 & 2.6 & 2.9 & 1.5 & 2.3 & 2.59 & 2.96 & 2.90 \\
\hline Role-Physical & 6.2 & 5.6 & 1.7 & 2.4 & 1.0 & 0.7 & & & \\
\hline Vitality & 7.2 & 6.0 & 5.7 & 3.1 & 3.9 & 1.0 & 2.80 & 3.20 & 3.13 \\
\hline Role-Emotional & 7.0 & 6.9 & 2.9 & -1.3 & 3.7 & -2.4 & & & \\
\hline Mental Health & 5.8 & 5.7 & 3.4 & -0.2 & 3.2 & 0.9 & & & \\
\hline Social Functioning & 6.4 & 5.8 & 1.4 & 1.0 & 0.5 & -1.5 & & & \\
\hline Bodily Pain & 5.7 & 5.6 & 2.1 & -1.4 & -0.2 & -3.0 & & & \\
\hline General Health & 4.8 & 4.8 & 3.1 & -2.2 & -1.5 & -2.2 & & & \\
\hline $\begin{array}{l}\text { Physical Component } \\
\text { Summary score }\end{array}$ & 4.2 & 4.7 & 2.0 & 1.5 & -0.8 & 0.0 & 2.19 & 2.51 & 2.45 \\
\hline $\begin{array}{l}\text { Mental Component } \\
\text { Summary score }\end{array}$ & 5.7 & 5.8 & 3.6 & -0.5 & 3.8 & -1.3 & & & \\
\hline
\end{tabular}

Abbreviations: FACT-An Functional Assessment of Cancer Therapy-Anemia, SD standard deviation, SEM standard error of measurement, SF-36 Medical Outcomes Survey Short Form-36 
Table 7 FACT-An: Important Change Score Estimates Using Distribution-based, anchor-based, and Linking Methods

\begin{tabular}{|c|c|c|c|c|c|c|c|c|c|c|c|}
\hline $\begin{array}{l}\text { FACT-An } \\
\text { total/ } \\
\text { subscale } \\
\end{array}$ & $\begin{array}{l}1 \\
\text { SEM }\end{array}$ & $\begin{array}{l}0.5 \\
\text { SD }\end{array}$ & $\begin{array}{l}\text { Vitality 3- } \\
\text { 4, Week } 9\end{array}$ & $\begin{array}{l}\text { Vitality } 3-4, \\
\text { Week 13/17 }\end{array}$ & $\begin{array}{l}\text { Physical } \\
\text { functioning 2.8- } \\
4.2 \text {, Week } 9\end{array}$ & $\begin{array}{l}\text { Physical functioning } \\
2.8-4.2 \text {, Week } 13 / 17\end{array}$ & $\begin{array}{l}\text { PCS 2- } \\
4, \text { Week } \\
9\end{array}$ & $\begin{array}{l}\text { PCS 2-4, } \\
\text { Week 13/ } \\
17\end{array}$ & $\begin{array}{l}\text { Linking } \\
\text { vitality }\end{array}$ & $\begin{array}{l}\text { Linking } \\
\text { physical } \\
\text { functioning }\end{array}$ & $\begin{array}{l}\text { Linking } \\
\text { PCS }\end{array}$ \\
\hline Total & 10.4 & 15.0 & 8.7 & 7.8 & 4.8 & 9.1 & 4.4 & 7.1 & 7.50 & 8.11 & 6.38 \\
\hline $\begin{array}{l}\text { Anemia } \\
\text { subscale }\end{array}$ & 6.2 & 7.5 & 5.2 & 4.2 & 1.3 & 5.5 & 2.5 & 4.7 & 3.75 & 4.05 & 3.19 \\
\hline $\begin{array}{l}\text { Fatigue } \\
\text { subscale }\end{array}$ & 5.2 & 5.7 & 4.0 & 3.2 & 2.1 & 3.9 & 2.1 & 3.6 & 2.88 & 3.11 & 2.45 \\
\hline General & 6.4 & 8.5 & 3.6 & 3.6 & 3.5 & 3.6 & 1.9 & 2.4 & & & \\
\hline $\begin{array}{l}\text { Physical } \\
\text { Well-Being }\end{array}$ & 2.3 & 2.7 & 0.7 & 1.5 & -0.4 & 1.3 & 0.3 & 1.3 & & & \\
\hline $\begin{array}{l}\text { Functional } \\
\text { Well-Being }\end{array}$ & 2.7 & 3.3 & 0.6 & 0.4 & 1.7 & 2.4 & 0.0 & -0.4 & & & \\
\hline $\begin{array}{l}\text { Social Well- } \\
\text { Being }\end{array}$ & 2.8 & 2.9 & 0.9 & 0.7 & 0.5 & -0.5 & 0.9 & 1.7 & & & \\
\hline $\begin{array}{l}\text { Emotional } \\
\text { Well-Being }\end{array}$ & 2.5 & 2.4 & 1.2 & 1.0 & 1.7 & 0.3 & 0.7 & -0.2 & & & \\
\hline
\end{tabular}

Abbreviations: FACT-An Functional Assessment of Cancer Therapy-Anemia, PCS Physical Component Summary, SD standard deviation, SEM standard error of measurement

One flaw of the anchor-based approach is frequent reliance on small sample sizes, as was the case in this study $(n=14-29)$, with the anchor range increased to 2.8 to 4.2 for the SF-36 Physical Component Summary change score (as no participants achieved a score change between these values at either time point). The linking estimates were similar to the other anchor-based methods.

\section{Discussion}

Despite the relatively common use of the SF-36 in patients with anemia associated with CKD in clinical studies and clinical trials [6, 16-18, 20-23, 53, 54], the psychometric measurement properties of SF-36 have not previously been reported in this patient population. This study provides evidence of the reliability, validity, and responsiveness of the SF-36 measure, and the results support the use of the SF-36 to assess treatment efficacy in clinical trials in this patient population. For patients with anemia associated with CKD, tiredness, fatigue, and poor physical functioning each have a significant impact on HRQoL. Therefore, the Physical functioning and Vitality domains may prove particularly useful in assessing the major impacts of the treatment of anemia in these patients. For a more general assessment of physical impact, the Physical Component Summary can also be used.

Whereas the SF-36 was developed to measure overall HRQoL, the FACT-An Anemia subscale was developed specifically to capture the impact of anemia on HRQoL, with the shorter Fatigue and Anemia subscales capturing a major impact often noted in anemia. These subscales show particular promise for use as endpoints in the
CKD anemia population for capturing the main patient health issues related to anemia; the strong correlations between the SF-36 and FACT-An domains scores further support the validity of these measures when used in a CKD population with anemia. The FACT-An Total score also captures these impacts and combines them with a general measure of HRQoL (FACT-G); thus, the FACT-An Total score is useful as an overall summary of HRQoL that can capture impairment to well-being resulting from anemia to describe the full impact of CKD with anemia.

When separated by trial, baseline mean scores were similar for the Fatigue and Anemia domains but slightly higher in the non-dialysis group for the FACT-An Total score and the other subscale scores. Moreover, these results highlight a somewhat greater impact on those patients with CKD receiving dialysis (i.e., those at a more severe stage of kidney failure), especially across social, functional, and emotional domains.

The link between anemia and fatigue, and the impact of CKD anemia on physical functioning, are each highlighted by baseline scores that were comparable with those found in patients with cancer [55]. These links are underlined by the observation that the correlation with the $\mathrm{Hb}$ level grew stronger over the duration of the treatment period. Similar correlations between $\mathrm{Hb}$ level and fatigue have been reported in patients with cancer [57].

The baseline PRO scores generally indicated a somewhat greater impact on patients with CKD receiving dialysis compared with the non-dialysis group, across social, functional, emotional domains and FACT-Anemia and Fatigue subscale scores. The improvement in these scores was also generally larger in the dialysis 
population. However, such a pattern was not shown for the SF-36 scores.

Reliability, assessed by internal consistency and test-retest correlation coefficients, was demonstrated for the SF-36 domain and summary scores (Cronbach's alpha $=0.69-0.93 ;$ ICC $=0.64-0.83$ ), and the FACT-An Total and all subscale scores (Cronbach's alpha $=0.79$ 0.95 ; ICC $=0.72-0.88$ ). As expected, high convergent validity was demonstrated for domains measuring similar concepts.

The strong correlation between the Vitality domain with each of the FACT-An subscales was encouraging. As the Vitality domain had the strongest relationship with the FACT-An Total score and Anemia and Fatigue subscales, extra consideration was given to the use of this anchor in determining an important change score. Consequently, the following important change score estimates are recommended: FACT-An Total: $6-9$ points; Anemia: $3-5$ points; Fatigue: $2-4$ points.

The relatively high Vitality score in the present study is surprising given that a substantial degree of impairment was reported in previous studies of CKD patients with anemia [6, 7].

Known-groups validity was demonstrated for the selected key domains Physical Functioning, and Vitality with significant differences between groups defined using the FACT-An Total, Fatigue, and Anemia subscale scores. Similarly, the key FACT-An scores, i.e., the FACT-An Total, and Fatigue and Anemia subscale scores differed significantly when split by SF-36 scores. Correlations with $\mathrm{Hb}$ level were typically smaller, particularly at baseline, where the $\mathrm{Hb}$ level was constrained by the inclusion criteria. Hb level-defined groups produced mixed results, which is consistent with published data reporting that a modest relationship between PRO measures and $\mathrm{Hb}$ level has previously been shown, with fatigue and physical functioning measures demonstrating additional benefit beyond or in the absence of $\mathrm{Hb}$ level change [56-58].

In patients with cancer, the correlation between $\mathrm{Hb}$ level and measure of fatigue is moderate, albeit sufficiently high to support the use of $\mathrm{Hb}$ as a clinical anchor for validation purposes [41, 59]. Notably, Holzner et al. [58] identified differences in the Multi-dimensional Fatigue Inventory scores between patients with cancer and healthy subjects, despite both groups having a normal $\mathrm{Hb}$ range. Furthermore, patients with lung cancer grouped by FACT-Fatigue scale score (in tertiles) had no significant differences in $\mathrm{Hb}$ level but significant differences in physical functioning and psychological distress [56]. These findings highlight the importance of measures that capture concepts beyond $\mathrm{Hb}$ level change, as $\mathrm{Hb}$ is not the only indicator of disease burden in these patients (especially in light of improvement in PRO scores in the two trials). Specifically, in circumstances where objective clinical markers do not exclusively identify the treatment benefit, inclusion of validated PRO measures as additional measures of efficacy is important [15]. The low correlations with $\mathrm{Hb}$ level also indicate that in this study sample more factors influence quality of life than $\mathrm{Hb}$ alone. The important change score estimates were similar irrespective of whether anchor-based or linking-based approaches were used, which supports their validity [51]. The FACT-An and SF-36 estimates were also consistent with previously suggested values for these instruments [40, 41].

For use as an endpoint in clinical trials, a PRO instrument needs to be sensitive to changes in a patient's condition. Although mixed results were identified using $\mathrm{Hb}$ level to define responders/non-responders in HRQoL measures, responsiveness was demonstrated using SF-36-defined responders/non-responders for all FACT-An scores. Coupled with a change in mean scores from baseline to Week 13/17 in both the SF-36 and FACT-An, these findings support the use of the SF-36 domains, Physical functioning and vitality, and the FACT-An scores for measuring efficacy from the patient perspective.

Our analysis has several limitations, including use of trial designs were similar, but not identical; however, the purpose of our research was to evaluate of the SF-36 and FACT-An questionnaires in patients with ESRD, which was unlikely to be affected by differences in trial duration or time of questionnaire administration. Both questionnaires were administered according to instructions provided. Prior research has suggested timing during a trial has no significant effect on responses [60]. The analyses were limited by the unavailability of clinical anchors that were not included in the trial, such as patient and clinician overall assessment of changes that would be useful in assessing the measurement performance, and in particular responsiveness to change of the two instruments. Although pooling the data of the two trials both increased the sample size and the range of severity, the trial samples differed in several sociodemographic (age, gender, and ethnicity) and clinical (CKD history and comorbid conditions) characteristics. However, even smaller sample sizes would be observed for the anchor-based important change score analyses had the data not been pooled. Whilst the results provide good evidence of the measurement properties of the SF-36 and the FACT-An, additional evidence of validity and responsiveness, in a larger sample, and using other variables in the analyses, is desirable. Increasing the sample size would provide more confidence in the estimation of anchor-based important change scores, as small sample sizes (such as in this study) are more vulnerable to individual extreme values distorting the mean. Hence, the MID estimates should be regarded as 
provisional with need for further corroboration in future trials. Using data derived in a clinical trial for validation purposes makes it possible to get an estimate of the magnitude of change observed. This is important for the assessment of responsiveness to change. By deriving additional data on the measurement properties in future trials further evidence can be provided. Despite its limitations, this study has demonstrated that the Physical functioning domain of the SF 36 in particular and the FACT-An Fatigue and Anemia subscales are useful measures for capturing important aspects of HRQoL in patients with CKD associated with suffering from anemia.

The results of this study provide further evidence of the reliability, validity and responsiveness of the SF-36 and FACT-An in patients with CKD receiving and not receiving dialysis. Both measures have already been included as endpoints in clinical trials for anemia associated with CKD $[6,16,33]$.

\section{Conclusions}

When evaluating the impact of anemia on patients with CKD, the SF-36 domains Vitality and Physical functioning scores, and the FACT-An Total, Fatigue, and Anemia domain subscales show good evidence of reliability, validity, and responsiveness. The modest relationship observed between $\mathrm{Hb}$ level and HRQoL highlights the importance of capturing HRQoL data, given patients with CKD treated for anemia experienced an improvement in FACT-An and SF-36 scores. Thus, the SF-36 and FACT-An questionnaires may be suitable for assessing the benefit of treatment beyond changes in $\mathrm{Hb}$ level in patients with anemia associated with CKD.

\section{Abbreviations \\ ANCOVA: Analysis of covariance; CKD: Chronic kidney disease; \\ ESA: Erythropoiesis-stimulating agents; ESRD: End-stage renal disease; FACT- An: Functional assessment of cancer therapy-anemia; FACT-G: Functional assessment of cancer therapy-general; Hb: Hemoglobin; HIF: Hypoxia- inducing factor; HIF-PH: Hypoxia-inducing factor- prolyl hydroxylase; HRQOL: Health-related quality of life; ICC: Intraclass correlation coefficient; IV: Intravenous; MCS: Mental component summary; MID: Minimally important difference; PCS: Physical component summary; PRO: Patient-reported outcome; SD: Standard deviation; SEM: Standard error of measurement; SF- 36: Medical outcomes survey short form-36; US: United States}

\section{Acknowledgements \\ The authors thank Wen-Hung Chen, PhD (an employee at Evidera, Bethesda, $\mathrm{MD}$ at the time of contribution) for his contribution to planning the statis- tical analyses, and Ren Yu, MA (Evidera, Bethesda, MD) for her assistance in conducting the analyses. The data were provided from two clinical trials (Clinicaltrials.gov Identifier: NCT01244763 \& NCT01414075) conducted by FibroGen in partnership with Astellas. \\ Funding \\ The study was conducted by Evidera, a consultancy company paid by Astellas.}

\section{Availability of data and materials}

The datasets generated during and/or analysed during the current study are available from the corresponding author on reasonable request.

\section{Authors' contributions}

All authors were involved in the design and interpretation of the analyses. All authors contributed to the drafting of the manuscript. All authors read and approved the final manuscript.

\section{Ethics approval and consent to participate}

The two trials from which data were derived for this analysis, were registered at Clinicaltrials.gov (NCT00761657, NCT01244763), approved by all appropriate institutional review boards, conducted in accordance with the Declaration of Helsinki, and subjects provided written informed consent.

\section{Competing interests}

FvN is a former employee at Astellas Pharma. IW is employed by Evidera, and DT was employed by Evidera when this study was conducted. DC and FOF received payment from Astellas for their contribution to the design and interpretation of the analyses.

\section{Publisher's Note}

Springer Nature remains neutral with regard to jurisdictional claims in published maps and institutional affiliations.

\section{Author details}

${ }^{1}$ Yale University, New Haven, CT, USA. ${ }^{2}$ Formerly with Astellas Pharma BV, Sylviusweg 62, 2333, BE, Leiden, The Netherlands. 'Evidera, Metro Building, 6th Floor, 1 Butterwick, London, W6 8DL, UK. ${ }^{4}$ Formerly with Evidera, Metro Building, 6th Floor, 1 Butterwick, London, W6 8DL, UK. ${ }^{5}$ Department of Medical Social Sciences, Northwestern University, Evanston, IL, USA.

Received: 6 March 2017 Accepted: 13 May 2018

Published online: 31 May 2018

\section{References}

1. Stauffer ME, Fan T. Prevalence of anemia in chronic kidney disease in the United States. PLoS One. 2014;9(1):e84943.

2. Minutolo R, Locatelli F, Gallieni M, Bonofiglio R, Fuiano G, Oldrizzi L, Conte G, De Nicola L, Mangione F, Esposito P, Dal CA. Anaemia Management in non-dialysis Chronic Kidney Disease (CKD) patients. A Multicentre Prospective Study in Renal Clinics. Nephrol Dial Transplant. 2013;28(12):3035-45.

3. McFarlane SI, Chen SC, Whaley-Connell AT, Sowers JR, Vassalotti JA, Salifu $\mathrm{MO}$, et al. Prevalence and associations of anemia of CKD: kidney early evaluation program (KEEP) and National Health and nutrition examination survey (NHANES) 1999-2004. Am J Kidney Dis. 2008;51(4 Suppl 2):S46-55.

4. Alexander M, Kewalramani R, Agodoa I, Globe D. Association of anemia correction with health related quality of life in patients not on dialysis. Curr Med Res Opin. 2007;23(12):2997-3008.

5. Weisbord SD, Fried LF, Mor MK, Resnick AL, Unruh ML, Palevsky PM, et al. Renal provider recognition of symptoms in patients on maintenance hemodialysis. Clin J Am Soc Nephrol. 2007;2(5):960-7.

6. Johansen KL, Finkelstein FO, Revicki DA, Evans C, Wan S, Gitlin M, Agodoa IL. Systematic review of the impact of erythropoiesis-stimulating agents on fatigue in dialysis patients. Nephrol Dial Transplant. 2012;27(6):2418-25. https://doi.org/10.1093/ndt/gfr697. Epub 2011 Dec 20

7. Bonner A, Wellard S, Caltabiano M. The impact of fatigue on daily activity in people with chronic kidney disease. J Clin Nurs. 2010;19(21-22):3006-15.

8. Schatell D, Ellstrom-Calder A, Alt PS, Garland JS. Survey of CKD patients reveals significant GAPS in knowledge about kidney disease. Part 1. Nephrol News Issues. 2003;17(5):23-6.

9. Delano BG. Improvements in quality of life following treatment with r-HuEPO in anemic hemodialysis patients. Am J Kidney Dis. 1989;14(2 Suppl 1):14-8.

10. Dharmarajan TS, Norkus EP. Mild anemia and the risk of falls in older adults from nursing homes and the community. J Am Med Dir Assoc. 2004;5(6): 395-400.

11. Finkelstein FO, Story K, Firanek C, Mendelssohn D, Barre P, Takano T, et al. Health-related quality of life and hemoglobin levels in chronic kidney disease patients. Clin J Am Soc Nephrol. 2009;4(1):33-8.

12. Kamenetz Y, Beloosesky Y, Zeltzer C, Gotlieb D, Magazanik A, Fishman $P$, et al. Relationship between routine hematological parameters, serum IL-3, IL-6 and erythropoietin and mild anemia and degree of function in the elderly. Aging (Milano). 1998;10(1):32-8. 
13. Lefebvre P, Vekeman F, Sarokhan B, Enny C, Provenzano R, Cremieux PY. Relationship between hemoglobin level and quality of life in anemic patients with chronic kidney disease receiving epoetin alfa. Curr Med Res Opin. 2006;22(10):1929-37.

14. Covic A, Seica A, Gusbeth-Tatomir P, Goldsmith D. Hemoglobin normalization trials in chronic kidney disease: what should we learn about quality of life as an end point? J Nephrol. 2008;21(4):478-84.

15. Dinan MA, Compton KL, Dhillon JK, Hammill BG, Dewitt EM, Weinfurt KP, et al. Use of patient-reported outcomes in randomized, double-blind, placebocontrolled clinical trials. Med Care. 2011;49(4):415-9.

16. Gandra SR, Finkelstein FO, Bennett AV, Lewis EF, Brazg T, Martin ML. Impact of erythropoiesis-stimulating agents on energy and physical function in nondialysis CKD patients with anemia: a systematic review. Am J Kidney Dis. 2010;55(3):519-34

17. Besarab A, Bolton WK, Browne JK, Egrie JC, Nissenson AR, Okamoto DM, et al. The effects of normal as compared with low hematocrit values in patients with cardiac disease who are receiving hemodialysis and epoetin. N Engl J Med. 1998;339(9):584-90

18. Drueke TB, Locatelli F, Clyne N, Eckardt KU, Macdougall IC, Tsakiris D, et al. Normalization of hemoglobin level in patients with chronic kidney disease and anemia. N Engl J Med. 2006;355(20):2071-84.

19. Foley RN, Parfrey PS, Morgan J, Barre PE, Campbell P, Cartier P, et al. Effect of hemoglobin levels in hemodialysis patients with asymptomatic cardiomyopathy. Kidney Int. 2000;58(3):1325-35.

20. Levin A, Djurdjev O, Thompson C, Barrett B, Ethier J, Carlisle E, et al. Canadian randomized trial of hemoglobin maintenance to prevent or delay left ventricular mass growth in patients with CKD. Am J Kidney Dis. 2005;46(5):799-811.

21. Parfrey PS, Foley RN, Wittreich BH, Sullivan DJ, Zagari MJ, Frei D. Doubleblind comparison of full and partial anemia correction in incident hemodialysis patients without symptomatic heart disease. J Am Soc Nephrol. 2005;16(7):2180-9.

22. Ritz E, Laville M, Bilous RW, O'Donoghue D, Scherhag A, Burger U, et al. Target level for hemoglobin correction in patients with diabetes and CKD: primary results of the Anemia correction in diabetes (ACORD) study. Am J Kidney Dis. 2007:49(2):194-207.

23. Roger SD, McMahon LP, Clarkson A, Disney A, Harris D, Hawley C, et al. Effects of early and late intervention with epoetin alpha on left ventricular mass among patients with chronic kidney disease (stage 3 or 4): results of a randomized clinical trial. J Am Soc Nephrol. 2004; 15(1):148-56.

24. Rossert J, Levin A, Roger SD, Horl WH, Fouqueray B, Gassmann-Mayer C, et al. Effect of early correction of anemia on the progression of CKD. Am J Kidney Dis. 2006;47(5):738-50

25. Singh AK, Szczech L, Tang KL, Barnhart H, Sapp S, Wolfson M, et al. Correction of anemia with epoetin alfa in chronic kidney disease. N Engl J Med. 2006;355(20):2085-98

26. Martin ML, Patrick DL, Gandra SR, Bennett AV, Leidy NK, Nissenson AR, et al. Content validation of two SF-36 subscales for use in type 2 diabetes and non-dialysis chronic kidney disease-related anemia. Qual Life Res. 2011;20(6):889-901.

27. Korevaar JC, Merkus MP, Jansen MAM, Dekker FW, Boeschoten EW, Krediet RT for the NECOSAD-study group. Validation of the KDQOL-SFTM: A dialysistargeted health measure. Quality of Life Res. 2002;11:437-47.

28. Cella D. The functional assessment of Cancer therapy-Anemia (FACT-an) scale: a new tool for the assessment of outcomes in cancer anemia and fatigue. Semin Hematol. 1997;34(3 Suppl 2):13-9.

29. Yellen SB, Cella DF, Webster K, Blendowski C, Kaplan E. Measuring fatigue and other anemia-related symptoms with the functional assessment of Cancer therapy (FACT) measurement system. J Pain Symptom Manag. 1997;13(2):63-74.

30. Cruciani RA, Dvorkin E, Homel P, Culliney B, Malamud S, Lapin J, et al. Lcarnitine supplementation in patients with advanced cancer and carnitine deficiency: a double-blind, placebo-controlled study. J Pain Symptom Manag. 2009;37(4):622-31.

31. Milroy R, Bajetta E, van den Berg P, O'Brien ER, Perez-Manga G. Effects of epoetin alfa on anemia and patient-reported outcomes in patients with non-small cell lung cancer receiving chemotherapy: results of a European, multicenter, randomized, controlled study. European Journal of Clinical \& Medical Oncology. 2011;3(2):59-6.

32. Revicki DA, Brandenburg NA, Muus $P, Y u$ R, Knight R, Fenaux P. Health-related quality of life outcomes of lenalidomide in transfusion-dependent patients with low- or
Intermediate-1-risk myelodysplastic syndromes with a chromosome $5 q$ deletion: results from a randomized clinical trial. Leuk Res. 2013;37(3):259-65.

33. Roger SD, Jassal SV, Woodward MC, Soroka S, McMahon LP. A randomised single-blind study to improve health-related quality of life by treating anaemia of chronic kidney disease with Aranesp(R) (darbepoetin alfa) in older people: STIMULATE. Int Urol Nephrol. 2014;46(2):469-75.

34. European Medicines Agency (EMA). Reflection Paper on the Regulatory Guidance for the Use of Health-related Quality of Life (HRQL) Measures in the Evaluation of Medicinal Products. 2005.

35. Food and Drug Administration (FDA). Guidance for industry on patientreported outcome measures: use in medical product development to support labelling claims. Fed Reg. 2009;74FR 65132:65132-3.

36. Besarab A, Provenzano R, Hertel J, Zabaneh R, Klau SJ, Lee T, Leong R, Hemmerich S, Peony Yu K-HP, Neff TB. Randomized placebo-controlled doseranging and pharmacodynamics study of roxadustat (FG-4592) to treat anemia in nondialysis-dependent chronic kidney disease (NDD-CKD) patients. Nephrol Dial Transplant. 2015;30:1665-73. https://doi.org/10.1093/ndt/gfv302.

37. Provenzano R, Besarab A, Sun CH, Diamond SA, Durham JH, Cangiano JL, et al. Oral hypoxia-inducible factor prolyl hydroxylase inhibitor Roxadustat (FG4592) for the treatment of Anemia in patients with CKD. Clin J Am Soc Nephrol. 2016;11(6):982-91.

38. Provenzano R, Besarab A, Wright S, Dua S, Zeig S, Nguyen P, et al. Roxadustat (FG-4592) versus Epoetin alfa for Anemia in patients receiving maintenance hemodialysis: a phase 2, randomized, 6- to 19-week, openlabel, active-comparator, dose-ranging, safety and exploratory efficacy study. Am J Kidney Dis. 2016;67(6):912-24.

39. Ware JE Jr, Sherbourne CD. The MOS 36-item short-form health survey (SF-36). I. Conceptual framework and item selection. Med Care. 1992;30(6):473-83.

40. Maruish ME. User's manual for the SF-36v2 Health Survey (3rd ed.). Lincoln, RI: QualityMetric Incorporated; 2011.

41. Cella D, Eton DT, Lai JS, Peterman AH, Merkel DE. Combining anchor and distribution-based methods to derive minimal clinically important differences on the functional assessment of Cancer therapy (FACT) anemia and fatigue scales. J Pain Symptom Manag. 2002;24(6):547-61.

42. Pfeffer MA, Burdmann EA, Chen CY, Cooper ME, de Zeeuw D, Eckardt KU, et al. A trial of darbepoetin alfa in type 2 diabetes and chronic kidney disease. N Engl J Med. 2009;361(21):2019-32.

43. Leidy NK, Revicki DA, Geneste B. Recommendations for evaluating the validity of quality of life claims for labeling and promotion. Value Health. 1999;2(2):113-27.

44. Nunnally JC, Bernstein IH. Psychometric theory. 3rd ed. New York, NY: McGraw-Hill; 1994

45. Cronbach $\sqcup$. Coefficient alpha and the internal structure of test. Psychometrika. 1951;16(3):297-334.

46. Hays RD, Revicki DA. Reliability and validity, including responsiveness. In: Fayers PM, Hays RD, editors. Assessing quality of life in clinical trials. 2nd ed. New York NY: Oxford University Press; 2005. p. 25-39.

47. Cohen J. Statistical power analysis for the behavioral sciences. Second ed. Hillsdale, NJ: Lawrence Erlbaum; 1988.

48. Guyatt GH, Osoba D, Wu AW, Wyrwich KW, Norman GR. Clinical significance consensus meeting G. Methods to explain the clinical significance of health status measures. Mayo Clin Proc. 2002;77(4):371-83.

49. Coon CD, Cappelleri JC. Interpreting change in scores on patientreported outcome instruments. Therapeutic Innovation \& Regulatory Science. 2016;50(1):22-9.

50. Cicchetti DV. Guidelines, criteria, and rules of thumb for evaluating normed and standardized assessment instruments in psychology. Psychol Assess. 1994;6(4):284-90.

51. Revicki D, Hays RD, Cella D, Sloan J. Recommended methods for determining responsiveness and minimally important differences for patient-reported outcomes. J Clin Epidemiol. 2008;61(2):102-9.

52. Fayers PM, Hays RD. Don't middle your MIDs: regression to the mean shrinks estimates of minimally important differences. Qual Life Res. 2014;23(1):1-4.

53. Locatelli F, Del Vecchio L, Pozzoni P. Anemia and cardiovascular risk: the lesson of the CREATE trial. J Am Soc Nephrol. 2006;17(12 Suppl 3):S262-6.

54. Clement FM, Klarenbach S, Tonelli M, Johnson JA, Manns BJ. The impact of selecting a high hemoglobin target level on health-related quality of life for patients with chronic kidney disease: a systematic review and meta-analysis. Arch Intern Med. 2009;169(12):1104-12. 
55. Suzuki Y, Tokuda Y, Fujiwara Y, Minami H, Ohashi Y, Saijo N. Weekly epoetin beta maintains haemoglobin levels and improves quality of life in patients with non-myeloid malignancies receiving chemotherapy. Jpn J Clin Oncol. 2008:38(3):214-21.

56. Brown DJ, McMillan DC, Milroy R. The correlation between fatigue, physical function, the systemic inflammatory response, and psychological distress in patients with advanced lung cancer. Cancer. 2005;103(2):377-82.

57. Crawford J, Cella D, Cleeland CS, Cremieux PY, Demetri GD, Sarokhan BJ, et al. Relationship between changes in hemoglobin level and quality of life during chemotherapy in anemic cancer patients receiving epoetin alfa therapy. Cancer. 2002;95(4):888-95.

58. Holzner B, Kemmler G, Greil R, Kopp M, Zeimet A, Raderer M, et al. The impact of hemoglobin levels on fatigue and quality of life in cancer patients. Ann Oncol. 2002;13(6):965-73.

59. Cella D, Kallich J, McDermott $A, X u X$. The longitudinal relationship of hemoglobin, fatigue and quality of life in anemic cancer patients: results from five randomized clinical trials. Ann Oncol. 2004;15(6):979-86.

60. Lai J-S, Cook K, Stone A, Beaumont J, Cella D. Classical testing theory and item response theory/Rasch model to assess difference between patientreported fatigue using seven-day and four-week recall periods. J Clin Epidemiol. 2009;62(9):991-7.

Ready to submit your research? Choose BMC and benefit from:

- fast, convenient online submission

- thorough peer review by experienced researchers in your field

- rapid publication on acceptance

- support for research data, including large and complex data types

- gold Open Access which fosters wider collaboration and increased citations

- maximum visibility for your research: over $100 \mathrm{M}$ website views per year

At BMC, research is always in progress.

Learn more biomedcentral.com/submissions 